American Journal of Applied Sciences 4 (12): 1036-1039, 2007

ISSN 1546-9239

(C) 2007 Science Publications

\title{
Bending Moments Distribution at the Main Structural Elements of Skew Deck-Slab and Their Implementation on Cost Effectiveness
}

\author{
Maher Kakish \\ College of Engineering, Al- Balqa Applied University, Salt, Jordan
}

\begin{abstract}
The distribution of bending moments in T-beam deck slab varies from one T-beam to another. The design of T-beams should be based on the actual bending moments each beam is subjected to for the purpose of achieving economy especially in bridge deck slab, extended over big area. The saving in some cases is substantial due to reducing the quantities of steel and concrete.
\end{abstract}

Keywords: T-beam, bridge, skew angle, finite element, longitudinal moments

\section{INTRODUCTION}

Many methods used in analyzing such as grillage and finite element method. Generally, grillage analysis is the most common method used in bridge analysis. In this method the deck is represented by an equivalent grillage of beams. The finer grillage mesh, provide more accurate results. It was found that the results obtained from grillage analysis compared with experiments and more rigorous methods are accurate enough for design purposes. If the load is concentrated on an area which is much smaller than the grillage mesh, the concentration of moments and torque cannot be given by this method and the influence charts described in Puncher ${ }^{[1]}$ can be used. The orientation of the longitudinal members should be always parallel to the free edges while the orientation of transverse members can be either parallel to the supports or orthogonal to the longitudinal beams. According to $\mathrm{CCA}^{[2]}$ the orthogonal mesh is cumbersome in input data but the output moments results Mx, My and Mxy can be used directly in the Wood- Armer equations as in Hambly ${ }^{[3]}$ to calculate the steel required in any direction.

The grillage analogy has become popular because of the following reasons:

- It can be used in cases where the bridges exhibits complicating features such as a heavy skew, edge stiffening and deep hunches over supports

- The representation of a bridge as a grillage is ideally suited to carrying out the necessary calculations associated with analysis and design on a digital computer

- The grillage representation is conductive to giving the designer an idea bout the structure behavior of the bridge and the manner in which bridge loading is distributed and eventually taken to the supports [4].

It is a horizontal grid consisting of the main (longitudinal) and cross (transverse) girders are orthogonally intersecting and is subjected to vertical loads only. Each of the longitudinal girders having flexural stiffness (EI), torsional stiffness (GJ) and length (L). The longitudinals girder are spaced a distance (h) apart and are interconnected by a number of equally spaced transverse beams each of which has flexural stiffness $\left(\mathrm{EI}_{\mathrm{T}}\right)$ and torisonal stiffness $\left(\mathrm{GJ}_{\mathrm{T}}\right)$ [4].

The other method used in modeling the bridges is the finite element method. The finite element method is a well known tool for the solution of complicated structural engineering problems, as it is capable of accommodating many complexities in the solution. In this method, the actual continuum is replaced by an equivalent idealized structure composed of discrete elements, referred to as finite elements, connected together at a number of nodes.

The finite elements method was first applied to problems of plane stress, using triangular and rectangular element. The method has since been extended and we can now use triangular and rectangular elements in plate bending, tetrahedron and hexahedron in three-dimensional stress analysis, and curved elements in singly or doubly curved shell problems. Thus the finite element method may be seen to be very general in application and it is sometimes the only valid analysis for difficult deck problems.

The finite element method is a numerical method with powerful technique for solution of complicated structural engineering problems. It most accurately predicted the bridge behavior under the truck axle loading ${ }^{[5]}$.

Corresponding Author: Maher Kakish Associate professor collage of engineering Al-Balqa Applied University 
The finite element method involves subdividing the actual structure into a suitable number of sub-regions that are called finite elements. These elements can be in the form of line elements, two dimensional elements and three-dimensional elements to represent the structure. The intersection between the elements are called nodal points in one dimensional problems where in two and three-dimensional problems are called nodal line and nodal planes respectively.

At the nodes, degrees of freedom (which are usually in the form of the nodal displacement and/ or their derivatives, stresses, or combinations of these) are assigned. Models which use displacements are called displacement models and some models use stresses defined at the nodal points as unknown. Models based on stresses are called force or equilibrium models, while those based on combinations of both displacements and stresses are termed mixed models or hybrid models ${ }^{[6]}$.

Displacements are the most commonly used nodal variable, with most general purpose programs limiting their nodal degree of freedom to just displacements. A number of displacement functions such as polynomials and trigonometric series can be assumed, especially polynomials because of the ease and simplification they provide in the finite element formulation.

To develop the element matrix, it is much easier to apply a work or energy method. The principle of virtual work, the principle of minimum potential energy and castigliano's theorem are methods frequently used for the purpose of derivation of element equation.

The finite element method has a number of advantages, they include the ability to ${ }^{[7]:}$

- Model irregularly shaped bodies and composed of several different materials.

- Handle general load condition and unlimited numbers and kinds of boundary conditions.

- Include dynamic effects.

- Handle nonlinear behavior existing with large deformation and nonlinear materials.

This method needs more time and efforts in modeling than the grillage. The results obtained from the finite element method depends on the mesh size but by using optimization of the mesh the results of this method are considered more accurate than grillage.

The finite element method is a well-known tool for the solution of complicated structural engineering problems, as it is capable of accommodating many complexities in the solution. In this method, the actual continuum is replaced by an equivalent idealized structure composed of discrete elements, referred to as finite elements, connected together at a number of nodes.

The finite element method was first applied to problem of plane stress, using triangular and rectangular elements. The method has since been extended and we can now use triangular and rectangular elements in plate bending, tetrahedron and hexahedron in three-dimensional stress analysis, and curved elements in singly or doubly curved shell problems. Thus the finite element method may be seen to be very general in application and it is sometimes the only valid analysis for difficult deck problems.

Tiedman ${ }^{[8]}$ shows the finite element method is a numerical method with powerful technique for solution of complicated structural engineering problems. It most accurately predicted the bridge behavior under the truck axle loading.

Qaqish ${ }^{[9]}$ presents the effect of skew angle on distribution of bending moments in bridge slabs.

Qaqish ${ }^{[10]}$ presents comparison between finite element method and AASHTO specification for the design of Tbeam bridge.

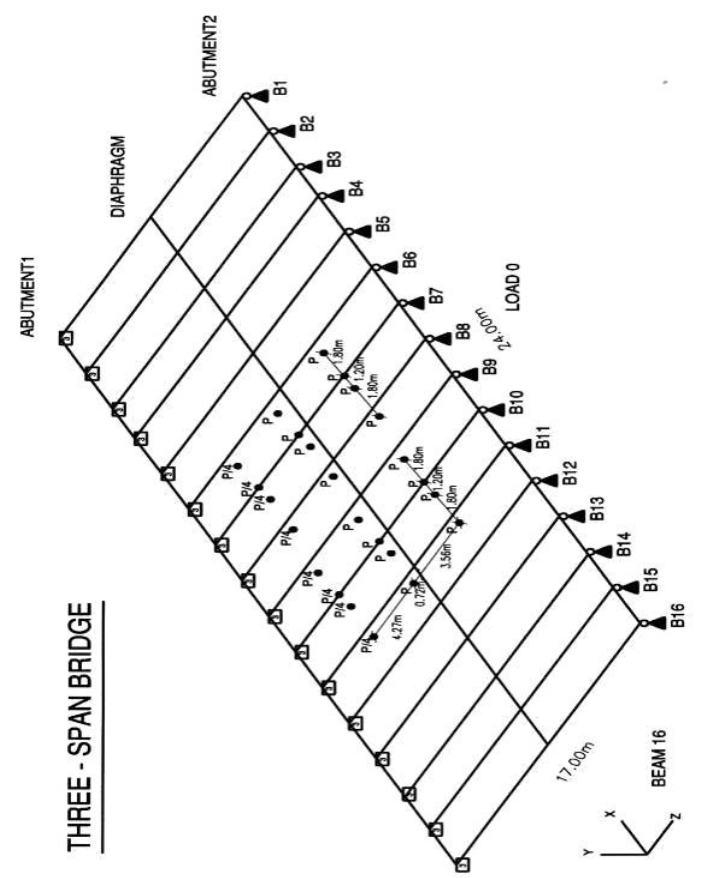

The bridge is analyzed by using the finite element method.

Table (1) shows the maximum bending moments and shear forces for different beams. 
Table 1: Maximum Moment and Shearing Force of Different Beams:

\begin{tabular}{ccc}
\hline Beam 1 & $\begin{array}{c}\text { Bending Moment } \\
\text { KN. M }\end{array}$ & $\begin{array}{c}\text { Shearing Force } \\
\text { KN }\end{array}$ \\
\hline 1 & 2224 & 589.3 \\
2 & 2446.2 & 616 \\
3 & 2802.1 & 638 \\
4 & 3233.5 & 743.6 \\
5 & 3558.16 & 797 \\
6 & 3869.5 & 850 \\
7 & 4136 & 903 \\
8 & 4447.7 & 1062.3 \\
9 & 4447.7 & 1062.3 \\
10 & 4136 & 903 \\
11 & 3869.5 & 850 \\
12 & 3558.16 & 797 \\
13 & 3233.5 & 743.6 \\
14 & 2802.1 & 638 \\
15 & 2446.2 & 616 \\
16 & 2224 & 589.3 \\
\hline
\end{tabular}

The maximum bending moments and shearing forces distributions are shown in Figs. 4 and 5. The values of bending moments and shearing forces are drawn in relative to maximum bending moment and shearing force at Beams 8 and 9 as shown in Figs. 6 and 7 .

It can be noticed that the difference in bending moments and shears is noticeable and the design of each beam should be carried out according to the actual bending moments the structure is subjected to for achieving economy especially when these beams will not be exposed to such loads and the area of deck slab is extended over big area.

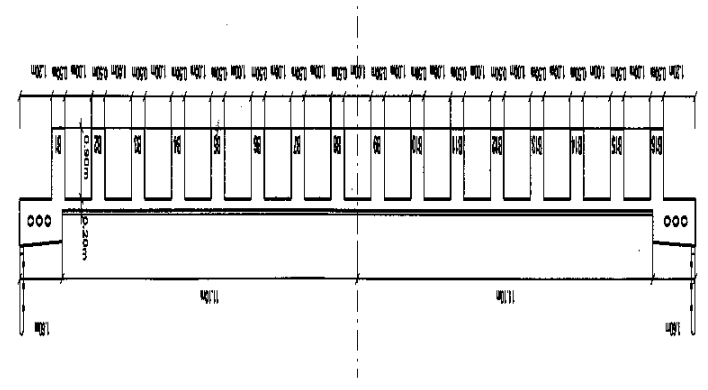

Fig. 2: Transverse section of bridge

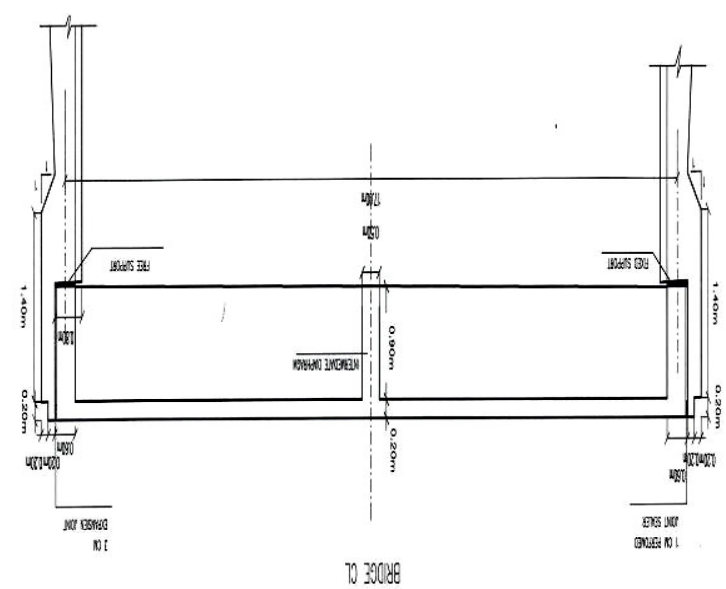

Fig. 3: longitudinal section of Bridge

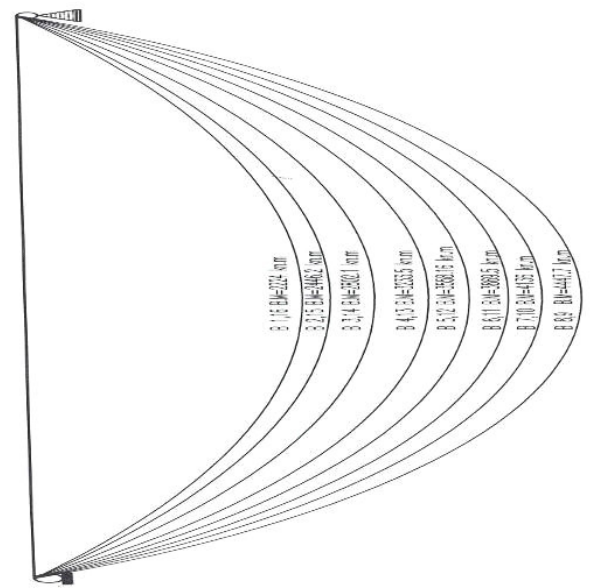

Fig. 4: Bending Moments at Different Beams

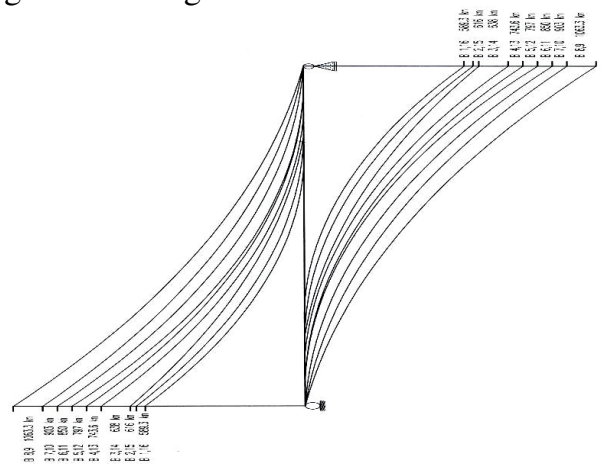

Fig. 5: Shearing Force at Different Beams 


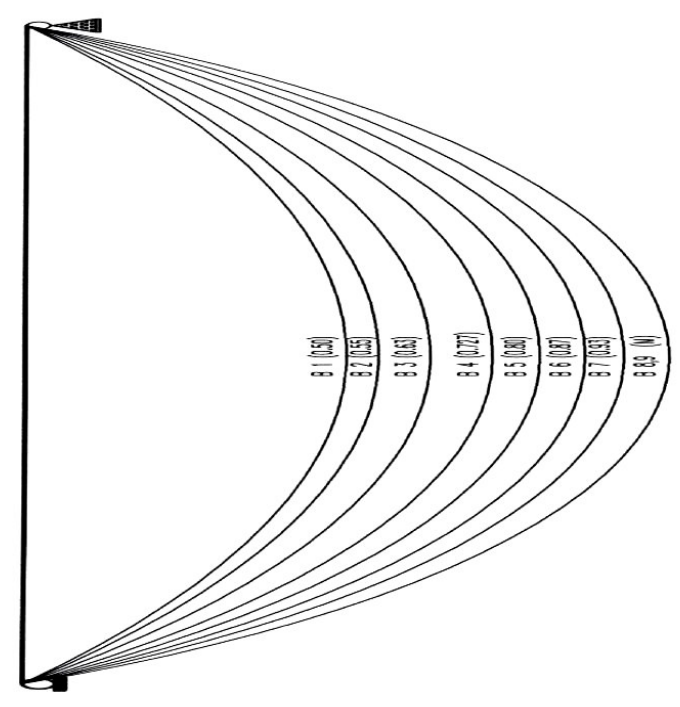

Fig. 6: Distribution of Bending Moments for all

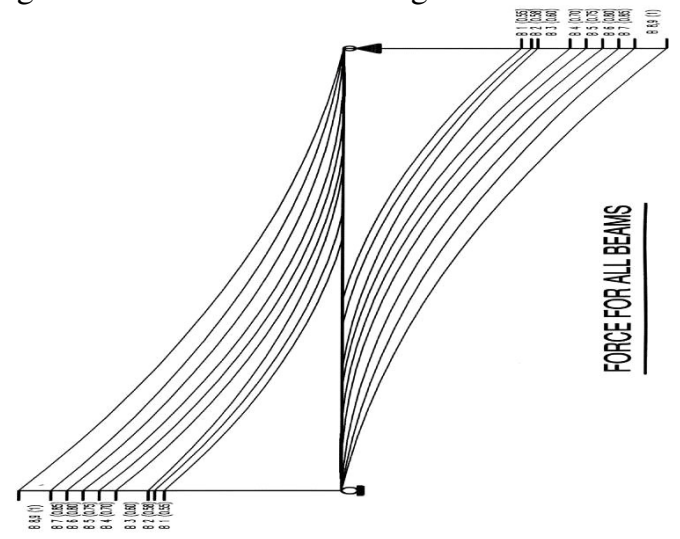

Fig. 7: Distribution of Shearing Force for all Beams

\section{CONCLUSION}

The design of bridge deck slab should be carried out in a structural computer model where the longitudinal beams subjected to vertical wheel loadings should be designed on the bending moments and shearing force these girders are subjected to. While the girders which they are not subjected to these truck loadings should be designed for the actual loadings they are applied on these girders. This method will achieve economy especially in places where the deck slab is extended over big area. The vertical displacements are varied from one longitudinal girder to the other and even these displacements are related to the actual bending moments these girders are subjected to. So chambering is also different from one longitudinal beam to the other which makes the constructions cheaper as some of these longitudinal beams do not need such chambering due to small vertical displacement

\section{REFERENCES}

1. Puncher, A. 1964, Influence Surface of Elastic Plates, First Edition, Springer Verlag, Wien and New York.

2. Cement \& Concrete Association, Construction Industry Research and Information Association,Recommendations on the use of Grillage Analysis for Slab and Pseudo-Slab Bridge Decks, London, SW1WOAQ, 1973.

3. Hambly, Edmun C. 1976. Bridges Deck Behaviour, First Edition Chapman \& Hall, London. PP. 170.

4. Jaeger, L.G., and Bakht, B., The Grillage Analogy in Bridge Analysis, Canadian Journal of Civil Engineering, Vol.9, Part 2, 1982, pp.224-235.

5. American Association of State Highway and Transportation Officials, AASHTO: Standard Specification for Highway Bridges, $17^{\text {th }}$ Edition, Washington, 2002.

6. Beckett, D.: An Introduction to Structural Design, Vol. 1, Surrey University Press, 1973, PP. 26-33.

7. Bakht, B. and Jaeger, L. G. Bridge Analysis Simplified, McGraw Hill Book Company, New York, 1985, PP. 24-27.

8. Tiedman, J. Albrecht, P. and Cayes, L. 1993. Behavior of Two-Span Continuous Bridge Under Truck Axle Loading. Journal of Structure Engineering, 119 (4): 1234-1250

9. Qaqish, M. S. Effect of Skew Angle on Distribution of Bending Moments in Bridge Slabs, Journal of Applied Sciences, 2005

10. Qaqish, M. S. Comparison Between Finite Element Method and AASHTO Specification for the Design of T-Beam Bridge, European Journal of Scientific Research, 2005. Staad. Pro, Research Engineers Crop. Headquarters, 22700 Savi Ranch Pkwy. Yorba Linda, CA 92887 